\title{
Oral Health Status in a Group of Patients with Type 2 Diabetes Mellitus
}

\author{
Aranka Ilea ${ }^{1}$, Adela Cristina Lazăr ${ }^{1}$, Andreeas-Vasile Bojor ${ }^{2}$, Georgeta Victoria Inceu ${ }^{3}$, Anca Ștefania Mesaros ${ }^{4 *}$, \\ Radu Septimiu Câmpian ${ }^{1}$, Anida-Maria Băbțan ${ }^{1}$, Nausica Bianca Petrescư ${ }^{1}$ and Adina Bianca Boșca ${ }^{5}$ \\ ${ }^{1}$ Department of Oral Rehabilitation, Oral Health and Dental Office Management, Faculty of Dentistry, "Iuliu Hațieganu" University of Medicine and \\ Pharmacy, Cluj-Napoca, Romania
}

${ }^{2}$ Postgraduate student of Faculty of Dentistry, luliu Hațieganu University of Medicine and Pharmacy, Romania

${ }^{3}$ Department of Diabetes, Iuliu Hațieganu University of Medicine and Pharmacy, Romania

${ }^{4}$ Department of Dental Propedeutics and Esthetics, Iuliu Hațieganu University of Medicine and Pharmacy, Romania

${ }^{5}$ Department of Histology, Iuliu Hațieganu University of Medicine and Pharmacy, Romania

Submission: December 17, 2018; Published: January 17, 2019

*Corresponding author: Anca Ștefania Mesaros, Department of Dental Propedeutics and Esthetics, Faculty of Dentistry, Iuliu Hațieganu University of Medicine and Pharmacy, Cluj-Napoca, Romania

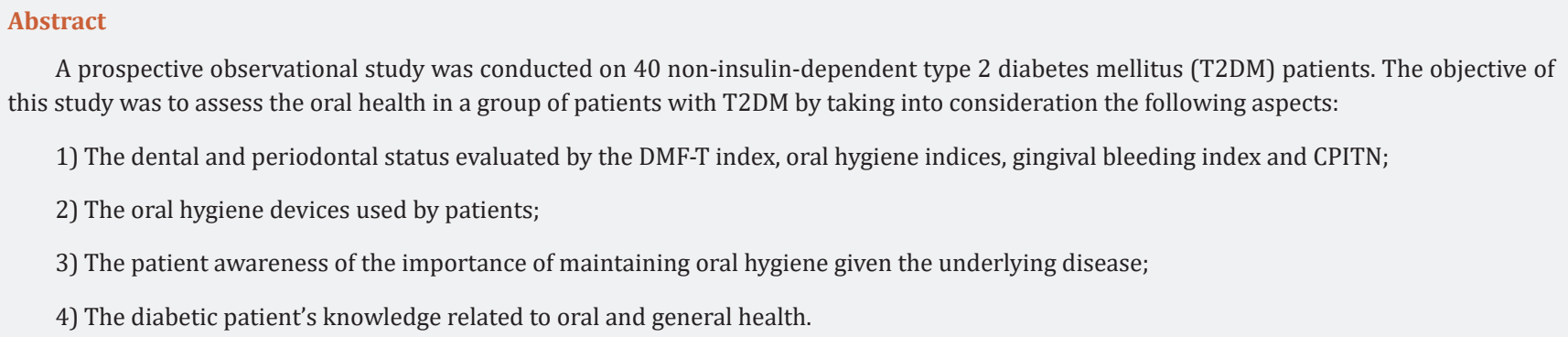

A prospective observational study was conducted on 40 non-insulin-dependent type 2 diabetes mellitus (T2DM) patients. The objective of this study was to assess the oral health in a group of patients with T2DM by taking into consideration the following aspects:

1) The dental and periodontal status evaluated by the DMF-T index, oral hygiene indices, gingival bleeding index and CPITN;

2) The oral hygiene devices used by patients;

3) The patient awareness of the importance of maintaining oral hygiene given the underlying disease;

4) The diabetic patient's knowledge related to oral and general health.

Most patients in the study group were aged between 60 and 69 years and living in urban areas. Examination of oral hygiene showed that $48 \%$ of patients had unsatisfactory oral hygiene. Therefore, the prevalence of periodontal disease in the patients included in our study was of $49 \%$. Out of total number of patients, $13 \%$ patients were totally edentulous. Only $5 \%$ of the patients underwent periodical dental examination. In conclusion, our findings suggest that oral hygiene services provided by dentists could promote better oral hygiene and improved periodontal status in the local community, which might be beneficial for the control of diabetes mellitus.

Keywords: Diabetes mellitus; Oral health; Periodontitis; Gingival bleeding; Dental plaque

Abbreviations: ADA: American Diabetes Association; AGEs: Advanced Glycation End Products; BMI: Body Mass Index; CP: Chronic Periodontitis; CPITN: Community Periodontal Index Treatment Needs; DM: Diabetes Mellitus; DMF-T: Decay Missing Filled Teeth; GBI: Gingival Bleeding Index; IL-1/IL-6: Interleukin - 1, - 6; IR: Insulin Resistance; HbA1c: Hemoglobin A1c; HDL: High Density Lipoproteins; T2DM: Type 2 Diabetes Mellitus; TLRs: Toll-Like Receptors; TNF- $\alpha$ : Tumor Necrosis Factor Alpha; ROS: Reactive Oxygen Species; OHI: Oral Hygiene Index; WHO: World Health Organization

\section{Introduction}

Diabetes mellitus is a chronic disease caused by inherited and/ or acquired deficiency in insulin production by the pancreas, or by the improper response to insulin in the peripheral tissues. These dysfunctions result in increased concentrations of glucose in the blood, which in turn induce multisystem damage, particularly affecting the blood vessels and the nerves. Type 2 diabetes mellitus (T2DM) - formerly named non-insulin-dependent - is characterized by the body's inability to respond properly to insulin produced by the pancreas (insulin resistance). T2DM is much more common than type 1 and accounts for around $90 \%$ of all diabetes cases worldwide. It occurs most frequently in adults but has been noted in adolescents as well [1-3]. Due to global urbanization, the prevalence of DM has increased in the recent years. Globally, 415 million adults have diabetes, and by 2040 , this number will rise to 642 million $[3,4]$. Chronic periodontitis (CP) is one of the most common chronic infectious diseases affecting the periodontium and is characterized by destruction of the supporting structures of the teeth. According to literature, $46 \%$ of adults in the United States have periodontitis, and $8.9 \%$ have severe periodontitis $[4,5]$.

It is well known that there is a link between T2DM and CP [6-9]. Epidemiological studies have demonstrated that T2DM may increase the risk of CP [10-12]. Nevertheless, CP could be a risk factor in controlling the glycemia levels in diabetic patients 
$[13,14]$. Moreover, the periodontal inflammation is significantly higher in patients with chronic hyperglycemia (patients with prediabetes and with poorly-controlled T2DM) than in healthy controls $[15,16]$. One explanation is that chronic hyperglycemia increases the expression of toll-like receptors (TLRs) and proinflammatory cytokines (interleukin 1-beta IL-1 $\beta$ and tumor necrosis factor alpha TNF- $\alpha$ ) in periodontal tissues and aggravates periodontal inflammation [17]. Moreover, chronic hyperglycemia can induce oxidative stress that imbalance the production and inactivation of reactive oxygen species (ROS) [18]. Persistent hyperglycemia has been associated with increased formation and accumulation of advanced glycation end products (AGEs) in periodontal tissues resulting in severe periodontal inflammation $[19,20]$.

The objective of this study was to evaluate the oral health in a group of patients with T2DM taking into consideration the following aspects:

i. The dental and periodontal status assessed by the DMF-T index, oral hygiene indices, periodontal index and treatment needs for the community periodontal index (CPITN);

ii. The oral hygiene devices used by patients;

iii. The awareness of the importance of maintaining oral hygiene due to the underlying disease;

iv. The knowledge of patients with diabetes related to oral and general health.

\section{Material and Method}

A prospective observational study was conducted on 40 non-insulin-dependent T2DM patients from Medical Center of Diabetology Department. The approval no. 223/17.05.2017 was obtained from the Ethics Commission of UMPh "Iuliu Haţieganu" Cluj-Napoca. The inclusion criteria were: the written consent of the patient; diagnosis of T2DM. The exclusion criteria were: lack of agreement to participate in the study and other type of diabetes. From the patient's medical records, we collected the data about heredo-collateral, physiological and pathological personal history. We also collected data regarding the presence of co-morbidities such as cardiovascular, digestive, respiratory, liver, kidney, nervous system, osteo-articular and dermatological disorders. Exo-oral and endo-oral clinical examinations were performed. The periodontal status was assessed by taking into account the following items:

Dental status evaluates and quantifies the dental caries prevalence, DMF-T index and oral hygiene index (OHI)

DMF-T index is the international index used to quantify the carious pathology and represents the number of teeth (T), decays (D), missing (M) and filled (F) from permanent dentition. According to the WHO, this index is quantified as follows: DMF-T between 0 and 1.1- very low, between 1.2 and 2.6 - low, 2.7 and 4.4 - moderate, 4.5 and 6.5 - high.

OHI (described by Green and Vermillion in 1964) measures the bacterial deposits and tartar deposits. It sums the values diagnosed from each individual 6 dental surfaces from each quadrant: vestibular surfaces of teeth 1.6 to 2.6; lingual surfaces of teeth 3.6 to 4.6 ; vestibular surfaces of teeth 1.1 to 3.1. Plaque index values were scored as: $0=$ no bacterial plaque deposits; $1=$ plaque deposit did not cover more than $1 / 3$ of the coronary area; $2=$ the plaque deposit covered more than $1 / 3$ but did not exceed $2 / 3$ of the coronary area; $3=$ plaque covered more than $2 / 3$ of the dental surface. The values of the tartar index were scored as: $0=$ no tartar; $1=$ supragingival tartar less than $1 / 3$ of the tooth surface; 2 = supragingival tartar more than $1 / 3$ and less than $2 / 3$ of the tooth surface or presence of subgingival tartar islets; 3 = supragingival tartar more than $2 / 3$ of the tooth surface or continuous subgingival tartar deposits. The OHI hygiene index was obtained by summing the plaque and tartar index values and expressed as follows: $\mathrm{OHI}$ between 0 and $1.2 \Rightarrow$ good oral hygiene, 1.3 and $3 \Rightarrow$ satisfactory oral hygiene, 3.1 and $6 \Rightarrow$ unsatisfactory oral hygiene.

\section{Periodontal status by evaluating and quantitating the GBI and CPITN.}

GBI was the quantification index of inflammation used by Ainamo and Bay (1975). The average score was expressed as a percentage. Score 0: absence of gingival inflammation; a score between 0.1-1.0: mild gingival inflammation; 1.1-2.0: moderate gingival inflammation; 2.1-3.0: severe gingival inflammation.

CPITN It is frequently used in both epidemiological and clinical evaluation. Dentition was divided into six sextants: 1.71.4, 1.3-2.3, 2.4-2.7, 4.7-4.4, 4.3-3.3, 3.4-3.7. Each sextant was assigned a code: 0 - healthy gum, 1- bleeding at the probing, 2 the presence of tartar supra and subgingival, iatrogenic marginal irritation, 3-periodontal pocket 4-5 $\mathrm{mm}$, 4- periodontal pocket of $6 \mathrm{~mm}$ or more. If a sextant did not contain at least two functional teeth it was not considered. Depending on the value of the code, there was a need for treatment as follows: TN0 no treatment needed; TN1- patient training for controlling the bacterial plaque and need for observing in time the evolution of the oral-dental hygiene; TN2- professional cleaning (scaling + professional brushing) was required, elimination of factors favoring the plaque retention and oral hygiene training; TN3periodontal pockets greater than $6 \mathrm{~mm}$ were present, treatment in this case was complex and included both therapeutic measures previously described; in case of severe loss of attachment, curettage and other surgical interventions were needed. The main disadvantage was that the gingival retraction was not measured. The dental examination included at least two outstanding teeth.

Chronic periodontitis can be classified by extension or severity (Flemming 1999). Regarding the extension, CP can 
be: localized (loss of attachment localized to $<30 \%$ of locus) or generalized (loss of attachment present to $>30 \%$ of the locus); regarding the severity, $\mathrm{CP}$ can be: mild - with loss of attachment measuring 1-2 mm, moderate - loss of attachment is 3-4 $\mathrm{mm}$, severe - loss of attachment $\geq 5 \mathrm{~mm}$ [21]

\section{Status of oral rehabilitation}

Different categories of edentulous patients in our study needed fixed or mobile prosthesis.

\section{Radiological investigations}

Imaging examinations were not performed; therefore the diagnosis was based mainly on clinical examination.

\section{Laboratory analyses}

According to ADA, the following parameters were assessed: Glycemia (72-108 mg/dL), HbA1c $(<7 \mathrm{mg} / \mathrm{dL})$, Creatinine $(0.6-$ $1.3 \mathrm{mg} / \mathrm{dL})$, Cholesterol $(<150 \mathrm{mg} / \mathrm{dL}), \mathrm{HDL}(<40 \mathrm{mg} / \mathrm{dL}$ in males and $<50 \mathrm{mg} / \mathrm{dL}$ in women) and Triglyceride $(<150 \mathrm{mg} /$ $\mathrm{dL})$. BMI ( $\mathrm{kg} / \mathrm{m} 2)$ was calculated as the ratio between the weight expressed in kilograms and the square of the height measured in meters [22].

\section{Results}

Of the patients enrolled in the study, $12 \%$ were between 40-49 years of age, $25 \%$ were between $50-59$ years of age, $50 \%$ were between $60-69$ years of age, $10 \%$ were between $70-79$ years of age and 3\% were between 80-89 years of age. Most patients in the study group were aged 60-69 years. Regarding the living conditions, $75 \%$ of patients came from urban areas and $25 \%$ of patients came from rural areas. Therefore, a greater proportion of diabetic patients lived in urban areas (about 2/3). Most patients in the study group (88\%) were non-smokers and $12 \%$ were smokers. Out of total number of patients, $13 \%$ patients were totally edentulous.

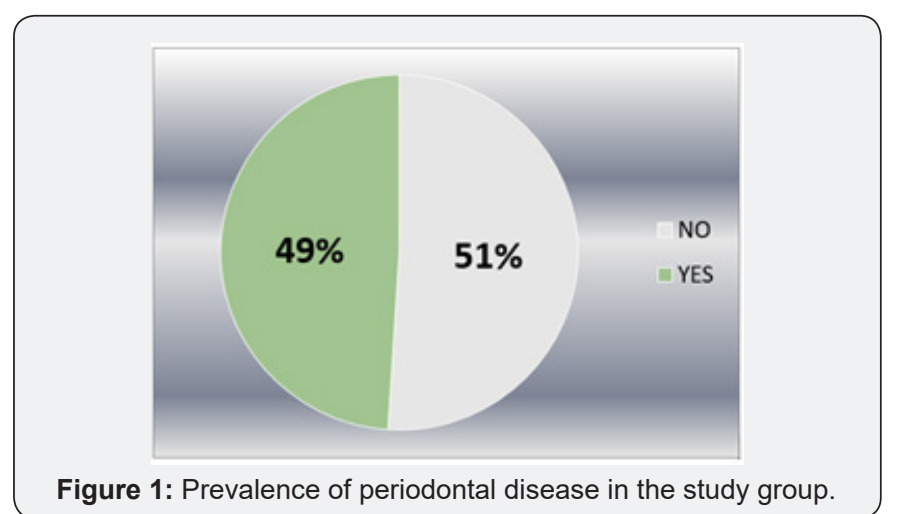

The prevalence of carious lesions was $58 \%$. Twelve patients had superficial oclusal cavities, six had class 2 dental cavities and six had extensive carious lesions. Regarding the oral hygiene, we found that $48 \%$ had unsatisfactory oral hygiene. Patients with unsatisfactory oral hygiene stated that they brushed their teeth twice a day, which led to the conclusion that they had been properly advised about the brushing frequency, but they did not apply the correct brushing technique. The prevalence of periodontal disease in the patients included in our study was of 49\% (Figure 1).

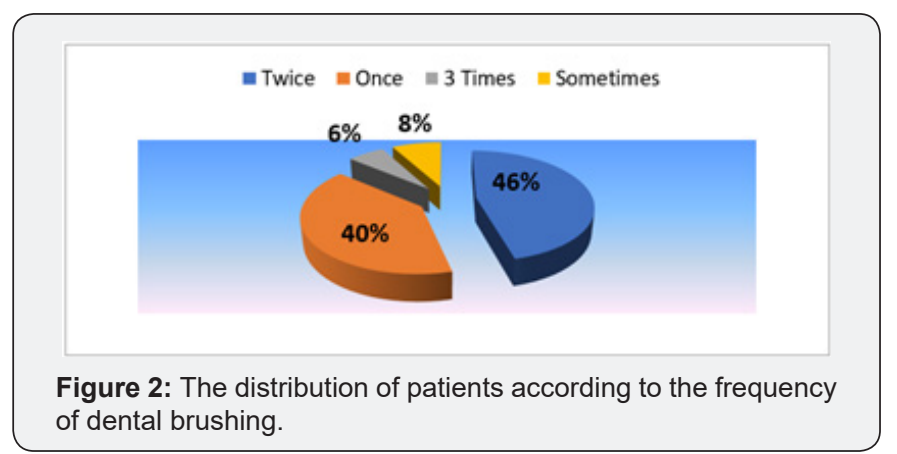

Out of the 35 dentate patients, $40 \%$ brushed their teeth once a day, $46 \%$ twice a day, $6 \%$ three times a day, and $8 \%$ brushed their teeth randomly, from time to time (Figure 2). Regarding the auxiliary oral hygiene methods used, 58\% patients used none, $8 \%$ patients used dental floss, $6 \%$ used interdental brushes, $25 \%$ patients used toothpicks and $3 \%$ used mouthwash (Figure 3).

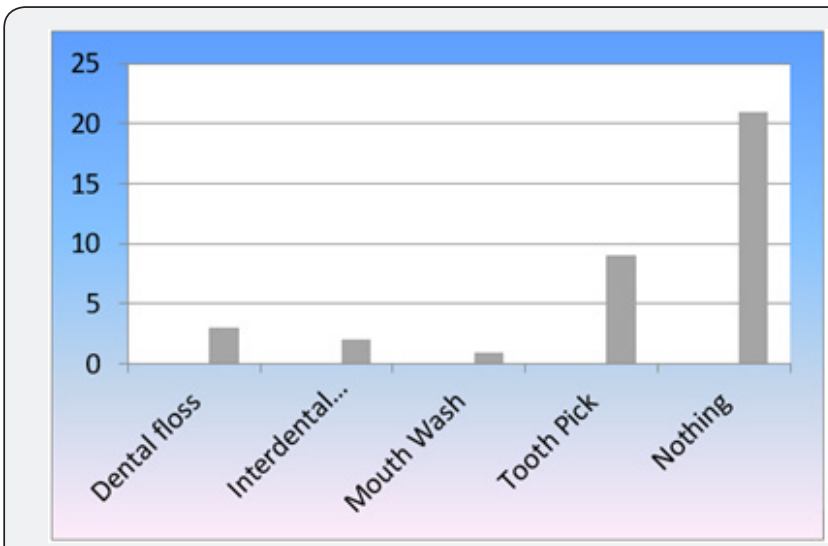

Figure 3: The distribution of patients according to the frequency of dental brushing.

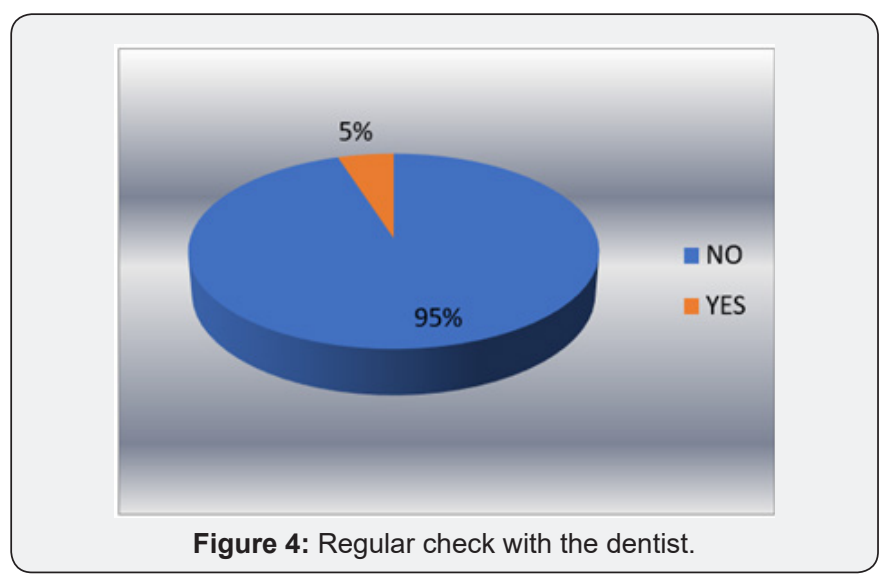

Only $5 \%$ of the patients underwent periodical dental examination (Figure 4). In the last year, $37 \%$ of the patients reported having been examined by the dentist, $7 \%$ of the patients had been examined only 1-2 years in advance, $13 \%$ of the patients had been examined only 3-5 years in advance, and 
most patients (43\%) had not been examined over the last 5 years. In the study, $31 \%$ of patients responded that they observed and worried about the gums bleeding during brushing, $17 \%$ were aware of the dental mobility, $26 \%$ noticed the presence of the dental cavities, $4 \%$ noticed that they had bad breath and $22 \%$ of patients did not report any changes in the oral cavity (Figure 5).

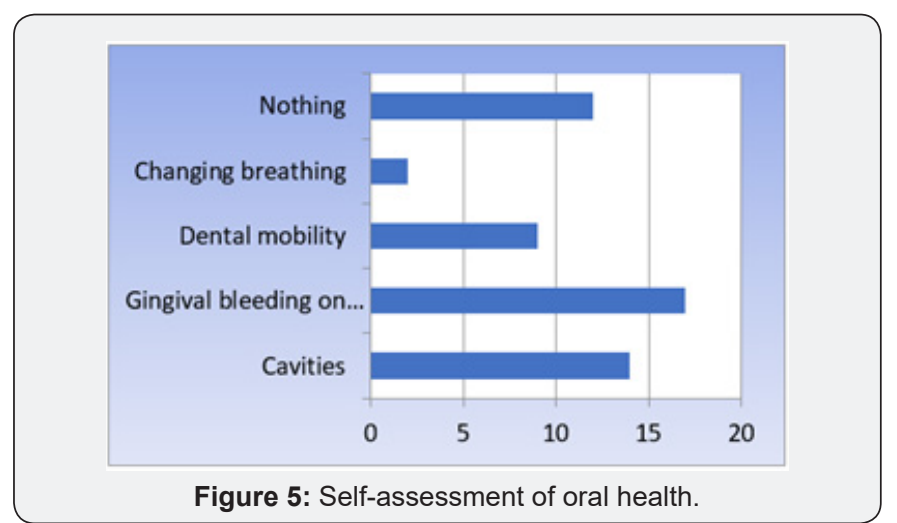

Upon examination of the periodontal status according to GBI bleeding index, in $18 \%$ of patients no gingival inflammation was registered, $44 \%$ of the patients had mild gingival inflammation, $32 \%$ had moderate gingival inflammation and $6 \%$ had severe gingival inflammation. The CPITN was Code 2 in $55 \%$ of patients, who had supragingival and subgingival dental plaque or iatrogenic marginal irritation, and Code 3 in $21 \%$ of patients who had periodontal pockets of 4-5 mm. Regarding the treatment recommended by the CPITN, most patients required professional hygiene (professional scaling and brushing), the elimination of factors that increased the bacterial plaque retention, plaque control and time tracking of the correctness of oral hygiene (Figure 6).

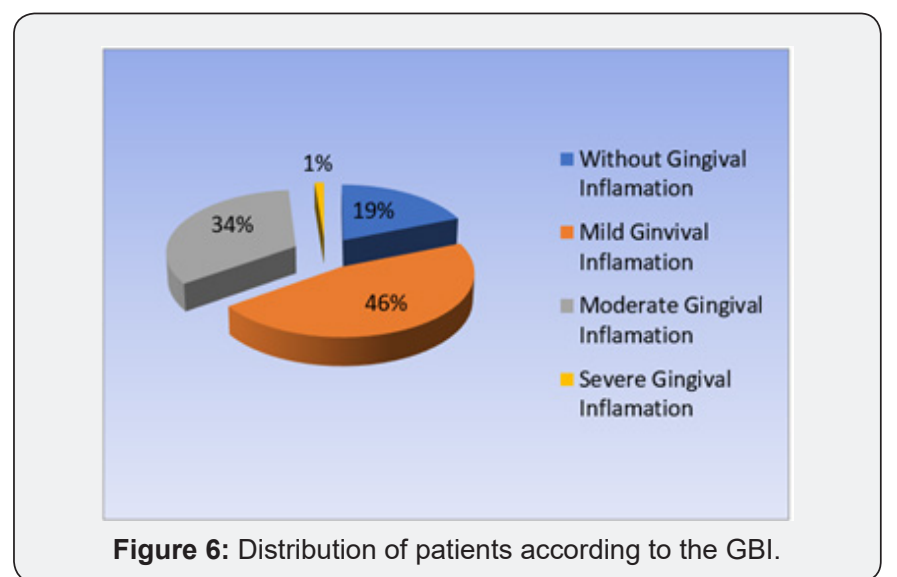

\section{Discussion}

Periodontal diseases are chronic microbial inflammations that affect the dental supporting structures [23]. The most common forms of periodontal disease are: gingivitis, which is present almost in all individuals, and periodontitis, a more severe form that affects $5 \%-15 \%$ of the global population. Periodontitis etiology is associated with the presence of dental plaque and calculus deposits in the periodontal tissues [24].
Recent data show that the periodontal disease could increase the risk of systemic diseases such as diabetes, because the presence of periodontal inflammation could be related to glycemic control in patients with type 2 diabetes mellitus. However, both healthy individuals and diabetic patients exhibit similar outcomes after periodontal therapy [24-26]. In the early 1990s, Loe [27] referred to periodontitis as the "sixth complication" of diabetes. Diabetes mellitus could induce various blood diseases, such as anemia and hemoglobinopathies [28-30].

It is believed that pro-inflammatory mediators, such as TNF- $\alpha$ and IL-6, are over-expressed at the inflamed periodontal sites due to the microbial factors or because of the host response. These mediators enter the systemic circulation, influence the function of insulin receptors and thus alter the insulin signaling [14]. In the 1990s, TNF- $\alpha$ was the first inflammatory marker that was thought to play a role in the development of obesityinduced insulin resistance [31]. Some studies have suggested that treatment with anti-TNF- $\alpha$ antibody could improve insulin sensitivity in IR patients $[32,33]$. Recently, a meta-analysis of 6 randomized-controlled trials and 3 controlled clinical trials revealed a significant difference in the action of TNF- $\alpha$ regarding the periodontal intervention versus the control group [34]. In a prospective blind intervention trial, the level of IL- 6 exhibited a significant decrease after periodontal treatment [35]. These results indicate that periodontal therapy can improve the quality of periodontium in the medium and long term, and can decrease the proinflammatory, insulin-antagonizing adipokines.

Furthermore, frequent scaling and professional dental brushing performed in the dental office is essential for the oral health of patients with T2DM [36]. A randomized clinical trial on T2DM patients demonstrated that, even if they were fit for periodontal surgery, the patients could be treated non-surgically by regular scaling and professional brushing [37]. Zare Javid, et al. [38] propose, as an adjuvant therapy for non-surgical periodontal treatment, the consumption of cranberry juice enriched with omega-3, which could be beneficial for improving the periodontal status in patients with T2DM and periodontal disease. In our study, related to the age and sex of patients, there was a low association with the periodontal disease and the presence of type 2 diabetes. Similarly, a recent review did not report a significant association between age, gender and medication adherence in diabetic patients [39]. Another study observed a significant effect of the education level on the rate of change in medication adherence [40]. These results are consistent with previous findings showing that people with lower education level had better adherence. It has been hypothesized that educated patients might have less trust in advice coming from physicians than patients with less education [41].

\section{Conclusion}

In summary, the close relationship between chronic periodontitis and the presence of type 2 diabetes in patients could be the trigger factor for both dental and periodontal 
problems. Prophylaxis and treatment of dental caries and periodontal disease are crucial for maintaining the oral health in patients with diabetes mellitus. The medical advice and the professional teeth cleaning provided by dentists could promote better oral hygiene, and improved periodontal status in the local community, and might also be efficient for monitoring type 2 diabetes mellitus.

\section{Acknowledgement}

Aranka Ilea, Adela Cristina Lazăr, Andreeas-Vasile Bojor and Georgeta Victoria Inceu have equal contributions as first authors of the article. This study was partially supported by COFUNDERA-HDHL ERANET Project, European and International Cooperation - Subprogram 3.2 - Horizon 2020, PNCDI III Program - Biomarkers for Nutrition and Health - "Innovative technological approaches for validation of salivary AGEs as novel biomarkers in evaluation of risk factors in diet-related diseases" (SALIVAGES), no 25/1.09.2017.

\section{References}

1. http://www.who.int/mediacentre/factsheets/fs138/en/

2. Afable A, Karingula NS (2016) Evidence based review of type 2 diabetes prevention and management in low- and middle-income countries. World J Diabetes 7(10): 209-229.

3. IDF diabetes atlas (2015) International Diabetes Federation. ( $7^{\text {th }}$ edn) Local: International Diabetes Federation.

4. Shunqin WANG, Jingsong LIU, Junfeng Zhang, Jiancheng LIN, Shuyu YANG, et al. (2017) Glycemic control and adipokines after periodontal therapy in patients with Type 2 diabetes and chronic periodontitis. Braz Oral Res 31: e90.

5. Eke PI, Dye BA, Wei L, Slade GD, Thornton-Evans GO, et al. (2015) Update on prevalence of periodontitis in adults in the United States: NHANES 2009 to 2012. J Periodontol 86(5): 611-622.

6. Preshaw PM, Alba AL, Herrera D, Jepsen S, Konstantinidis A, et al. (2012) Periodontitis and diabetes: a two-way relationship. Diabetologia 55(1): 21-31.

7. Mealey BL, Ocampo GL (2007) Diabetes mellitus and periodontal disease. J Periodontol 44(1): 127-153.

8. Casanova L, Hughes FJ, Preshaw PM (2014) Diabetes and periodontal disease: a two-way relationship. Br Dent J 217(8): 433-437.

9. Gurav AN (2016) Management of diabolical diabetes mellitus and periodontitis nexus: are we doing enough? World J Diabetes 7(4): 5066.

10. Rajhans NS, Kohad RM, Chaudhari VG, Mhaske NH (2011) A clinical study of the relationship between diabetes mellitus and periodontal disease. J Indian Soc Periodontol 15(4): 388-392.

11. Hong M, Kim HY, Seok H, Yeo CD, Kim YS, et al (2016) Prevalence and risk factors of periodontitis among adults with or without diabetes mellitus. Korean J Intern Med 31(5): 910-919.

12. Weinspach K, Staufenbiel I, Memenga-Nicksch S, Ernst S, Geurtsen W, et al. (2013) Level of information about the relationship between diabetes mellitus and periodontitis: results from a nationwide diabetes information program. Eur J Med Res 18(1): 6-13.

13. Khanuja PK, Narula SC, Rajput R, Sharma RK, Tewari S (2017) Association of periodontal disease with glycemic control in patients with type 2 diabetes in Indian population. Front Med 11(1): 110-119.
14. Santos Tunes R, Foss-Freitas MC, Nogueira-Filho GR (2010) Impact of periodontitis on the diabetes-related inflammatory status. J Can Dent Assoc 76: a35.

15. Costa KL, Taboza ZA, Angelino GB, Silveira VR, Montenegro R, et al (2017) The influence of periodontal disease on changes of glycated hemoglobin levels in type 2 diabetics: a retrospective cohort study. J Periodontol 88(1): 17-25.

16. Fernandes JK, Wiegand RE, Salinas CF, Grossi SG, Sanders JJ, et al. (2009) Periodontal disease status in gullah african americans with type 2 diabetes living in South Carolina. J Periodontol 80(7): 10621068.

17. Huang Y, Guo W, Zeng J, Chen G, Sun W, et al (2016) Prediabetes enhances periodontal inflammation consistent with activation of Tolllike receptor-mediated nuclear factorkB pathway in rats. J Periodontol 87(5): 64-74.

18. Bullon P, Newman HN, Battino M (2000) Obesity, diabetes mellitus, atherosclerosis and chronic periodontitis: a shared pathology via oxidative stress and mitochondrial dysfunction? Periodontol 2000 64(1): 139-153.

19. Pietropaoli D, Tatone C, D’Alessandro AM, Monaco A (2010) Possible involvement of advanced glycation end products in periodontal diseases. Int J Immunopathol Pharmacol 23(3): 683-691.

20. Mohammed A, Sameer M, Ali A, Nawwaf AL-HAM, Tariq A, et al. (2018) Periodontal parameters in prediabetes, type 2 diabetes mellitus, and non-diabetic patients. Braz Oral Res 32(81): 1-7.

21. Roman A (2010) Practica Parodontologiei Clinice: Editura Medicală Universitară "Iuliu Hațieganu" Cluj-Napoca.

22. Crăciun AM (2013) Compendiu de biochimie clinică și explorări de laborator. $\left(2^{\text {nd }}\right.$ edn). Cluj-Napoca: MEGA.

23. Pihlstrom BL, Michalowicz BS, Johnson NW (2005) Periodontal diseases. Lancet 366(9499): 1809-1820.

24. Demmer RT, Papapanou PN (2010) Epidemiologic patterns of chronic and aggressive periodontitis. Periodontol 2000 53: 28-44.

25. Kara G, Cifcibasi E, Karsidag K, Cintan S (2015) Short term effects of periodontal therapy on inflammatory markers in patients with type-2 diabetes. Saudi Med J 36(4): 469-476.

26. Hayashi I, Hasegawa A, Hayashi K, Suzuki T, Ishii M, et al. (2017) Effects of periodontal treatment on the medical status of patients with type 2 diabetes mellitus: a pilot study. BMC Oral Health 17(1): 77.

27. Loe H (1993) Periodontal disease. The sixth complication of diabetes mellitus. Diabetes Care 16(1): 329-334.

28. Mealey BL, Ocampo GL (2007) Diabetes mellitus and periodontal disease. J Periodontol 77(8): 1289-12303.

29. Phatlhane DV, Zemlin AE, Matsha TE, Hoffmann M, Naidoo N, et al. (2016) The iron status of a healthy south African adult population. Clin Chim Acta 460: 240-245.

30. Bird A, Ellis P, Wood K, Mathew C, Karabus C (1987) Inherited haemoglobin variants in a South African population. J Med Genet 24(4): 215-219.

31. Stephens JM, Lee J, Pilch PF (1997) Tumor necrosis factor- $\alpha$-induced insulin resistance in 3T3-L1 adipocytes is accompanied by a loss of insulin receptor substrate-1 and GLUT4 expression without a loss of insulin receptor-mediated signal transduction. J Biol Chem 272(2): 971-976.

32. Yazdani-Biuki B, Stelzl H, Brezinschek HP, Hermann J, Mueller T, et al. (2004) Improvement of insulin sensitivity in insulin resistant subjects during prolonged treatment with the anti-TNF-alpha antibody infliximab. Eur J Clin Invest 34(9): 641-642. 
33. Stanley TL, Zanni MV, Johnsen S, Rasheed S, Makimura H, et al. (2011) TNF-alpha antagonism with etanercept decreases glucose and increases the proportion of high molecular weight adiponectin in obese subjects with features of the metabolic syndrome. J Clin Endocrinol Metab 96(1): E146-150.

34. Artese HP, Foz AM, Rabelo MS, Gomes GH, Orlandi M, et al. (2015) Periodontal therapy and systemic inflammation in type 2 diabetes mellitus: a meta-analysis. PLoS One 10(5): e0128344.

35. D’Aiuto F, Parkar M, Andreou G, Suvan J, Brett PM, et al. (2004) Periodontitis and systemic inflammation: control of the local infection is associated with a reduction in serum inflammatory markers. J Dent Res 83(2): 156-160

36. Kim N-H, Lee G-Y, Park S-K, Kim Y-J, Lee M-Y, et al. (2017) Provision of oral hygiene services as a potential method for preventing periodontal disease and control hypertension and diabetes in a community health centre in Korea. Health Soc Care Community 26(3): e378-e385.

37. Mauri-Obradors E, Merlos A, Estrugo-Devesa A, Jané-Salas E, LópezLópez J, et al. (2018) Benefits of non-surgical periodontal treatment

This work is licensed under Creative

Commons Attribution 4.0 License

DOI: 10.19080/CTBEB.2019.17.555969 in patients with type 2 diabetes mellitus and chronic periodontitis: A randomized controlled trial. J Clin Periodontol 45(3): 345-353.

38. Zare Javid A, Maghsoumi-Norouzabad L, Ashrafzadeh E, Yousefimanesh HA, Zakerkish M, et al. (2018) Impact of Cranberry Juice Enriched with Omega-3 Fatty Acids Adjunct with Nonsurgical Periodontal Treatment on Metabolic Control and Periodontal Status in Type 2 Patients with Diabetes with Periodontal Disease. J Am Coll Nutr 37(1): 71-79.

39. Krass I, Schieback P, Dhippayom T (2015) Adherence to diabetes medication: a systematic review. Diabet Med 32(6): 725-737.

40. Gentil L, Vasiliadis H-M, Berbiche D, Préville M (2017) Impact of depression and anxiety disorders on adherence to oral hypoglycemics in older adults with diabetes mellitus in Canada. Eur J Ageing 14(2): 111-121.

41. Senior V, Marteau TM, Weinman J (2014) Genetic Risk Assessment for FH Trial (GRAFT) Study Group Self-reported adherence to cholesterollowering medication in patients with familial hypercholesterolaemia: the role of illness perceptions. Cardiovasc Drugs Ther 18(6): 475-481.

Your next submission with Juniper Publishers will reach you the below assets

- Quality Editorial service

- Swift Peer Review

- Reprints availability

- E-prints Service

- Manuscript Podcast for convenient understanding

- Global attainment for your research

- Manuscript accessibility in different formats

(Pdf, E-pub, Full Text, Audio)

- Unceasing customer service

Track the below URL for one-step submission https://juniperpublishers.com/online-submission.php 